\title{
COUPLED COINCIDENCE POINT RESULT IN PARTIALLY ORDERED GENERALIZED METRIC SPACES
}

\author{
VIZENDER SIHAG AND RAMESH KUMAR VATS
}

\begin{abstract}
The present study introduces the notion of compatibility in partially ordered Gmetric spaces and uses this perception to establish a coupled coincidence point result. Our effort extend the recent work of Choudhary and Maity [B. S. Choudhary, P. Maity, Coupled fixed point results in generalized metric spaces, Mathematical and Computer Modelling 54 (2011) 73-79]. The example demonstrates that our main result is an actual improvement over the results which are generalized
\end{abstract}

\section{Introduction}

The Banach contraction principle is most celebrated fixed point theorem. Mustafa and Sims [1, 2] introduced a improved version of the generalized metric space structure, which they called it as G-metric space and establish Banach contraction principle in this work. For more details on G-metric space, one can refer to the papers [1]-[11]. Fixed point theorems in partially ordered G-metric space have been considered in [8].

Studies on coupled fixed point problems in partially ordered metric spaces have received considerable attention in recent years. One of the reason of this interest is their potential applicability. Specifically, Bhaskar and Lakshmikanthan [16] established coupled fixed point for mixed monotone operator in partially ordered metric spaces. Afterward, Lakshmikanthan and Ciric [20] extended the results of [16] by furnishing coupled coincidence and coupled fixed point theorem for two commuting mappings having mixed g-monotone property. In a subsequent series, B. S. Choudhary and A. Kundu [26] introduced the concept of compatibility and proved the result of [20] under different set of condition.

Recently, Choudhary and Maity publish coupled fixed point results in partially ordered Gmetric spaces. Motivated by ([16], [20], [26] and [27]) we introduce the notion of compatibility

Corresponding author: Vizender Sihag.

2010 Mathematics Subject Classification. 47H10, 54H25.

Key words and phrases. Partially ordered set, coupled coincidence point, mixed g-monotone property, compatible mappings.

The authors are gratefully acknowledged to Council of Scientific and Industrial Research, Government of India, for providing financial assistant under research project no. 25(0197)/11/EMR-II. 
in partially ordered G-metric spaces and utilize this to prove a coupled coincidence point result for mixed g-monotone mapping. An illustrative example is discussed which shows that the above mentioned improvements are actual.

\section{Mathematical preliminaries}

Let $(X, \preccurlyeq)$ be partially ordered set and $F: X \rightarrow X$ be a mapping from $X$ to itself. The mapping $F$ is said to be non-decreasing if for all $x_{1}, x_{2} \in X, x_{1} \leq x_{2}$ implies $F\left(x_{1}\right) \leq F\left(x_{2}\right)$ and non-increasing, if for all $x_{1}, x_{2} \in X, x_{1} \leq x_{2}$ implies $F\left(x_{1}\right) \geq F\left(x_{2}\right)$.

In 2004, Mustafa and Sims [2] introduced the concept of $G$-metric spaces as follows:

Definition 2.1 ([2]). Let $X$ be a nonempty set and let $G: X \times X \times X \rightarrow R^{+}$be a function satisfying the following axioms:

$\left(G_{1}\right) G(x, y, z)=0$ if $x=y=z$,

$\left(G_{2}\right) \quad 0<G(x, x, y)$, for all $x, y \in X$ with $x \neq y$,

$\left(G_{3}\right) G(x, x, y) \leq G(x, y, z)$, for all $x, y, z \in X$ with $z \neq y$,

$\left(G_{4}\right) G(x, y, z)=G(x, z, y)=G(y, z, x)=\ldots$ (symmetry in all three variables),

$\left(G_{5}\right) G(x, y, z)=G(x, a, a)+G(a, y, z)$ for all $x, y, a, z \in X$ (rectangle inequality)

then the function $G$ is called a generalized metric on $X$ and the pair $(X, G)$ is called a G-metric space.

Definition $2.2([2])$. Let $(X, G)$ be a $G$-metric space and let $\left\{x_{n}\right\}$ a sequence of points in $X$, a point $x$ in $X$ is said to be the limit of the sequence $\left\{x_{n}\right\}$ if $\lim _{m, n \rightarrow \infty} G\left(x, x_{n}, x_{m}\right)=0$, and one says that sequence $\left\{x_{n}\right\}$ is $G$-convergent to $x$.

Thus, that if $x_{n} \rightarrow x$ or $\lim _{n \rightarrow \infty} x_{n}=x$ in a $G$-metric space $(X, G)$, then if for each $\varepsilon>0$, there exists a positive integer $N$ such that $G\left(x, x_{n}, x_{m}\right)<\varepsilon$ for all $m, n \geq N$.

Proposition $2.1([2])$. Let $(X, G)$ be a $G$-metric space. Then the following are equivalent:

(1) $\left\{x_{n}\right\}$ is $G$ convergent to $x$,

(2) $G\left(x_{n}, x_{n}, x\right) \rightarrow 0$ as $n \rightarrow \infty$,

(3) $G\left(x_{n}, x, x\right) \rightarrow 0$ as $n \rightarrow \infty$,

(4) $G\left(x_{m}, x_{n}, x\right) \rightarrow 0$ as $m, n \rightarrow \infty$.

Definition 2.3 ([4]). If $(X, G)$ and $\left(X_{1}, G_{1}\right)$ be two $G$-metric space and let $f:(X, G) \rightarrow\left(X_{1}, G_{1}\right)$ be a function, then $f$ is said to be $G$-continuous at a point $x_{0} \in X$ if given $\varepsilon>0$, there exists $\delta>0$, such that for $x, y \in X$ and $G\left(x_{0}, x, y\right)<\delta$ implies $G_{1}\left(f\left(x_{0}\right), f(x), f(y)\right)<\varepsilon$. A function $f$ is $G$-continuous at $X$ if and only if it is $G$-continuous at all $x_{0} \in X$ or function $f$ is said to 
be $G$-continuous at a point $x_{0} \in X$ if and only if it is $G$-sequentially continuous at $x_{0}$, that is, whenever $\left\{x_{n}\right\}$ is $G$-convergent to $x_{0},\left\{f\left(x_{n}\right)\right\}$ is $G$-convergent to $f\left(x_{0}\right)$.

Definition $2.4([2])$. Let $(X, G)$ be a $G$-metric space. A sequence $\left\{x_{n}\right\}$ is called $G$-Cauchy if, for each $\varepsilon>0$, there exists a positive integer $N$ such that $G\left(x_{n}, x_{m}, x_{l}\right)<\varepsilon$ for all $n, m, l \geq N$; i.e. if $G\left(x_{n}, x_{m}, x_{l}\right) \rightarrow 0$ as $n, m, l \rightarrow \infty$.

Proposition $2.2([2])$. If $(X, G)$ is a $G$-metric space then the following are equivalent:

(1) The sequence $\left\{x_{n}\right\}$ is G-Cauchy,

(2) for each $\varepsilon>0$, there exist a positive integer $N$ such that $G\left(x_{n}, x_{m}, x_{l}\right)<\varepsilon$ for all $n, m, l \geq N$.

Proposition 2.3 ([2]). Let $(X, G)$ be a G-metric space. Then the function $G(x, y, z)$ is jointly continuous in all three of its variables.

Definition 2.5 ([2]). A $G$-metric space $(X, G)$ is called a symmetric $G$-metric space if

$$
G(x, y, y)=G(y, x, x) \text { for all } x, y \text { in } X \text {. }
$$

Proposition 2.4 ([2]). Every $G$-metric space $(X, G)$ will defines a metric space $\left(X, d_{G}\right)$ by

(1) $d_{G}(x, y)=G(x, y, y)+G(y, x, x)$ for all $x, y$ in $X$.

If $(X, G)$ is a symmetric $G$-metric space, then

(2) $d_{G}(x, y)=2 G(x, y, y)$ for all $x, y$ in $X$.

However, if $(X, G)$ is not symmetric, then it follows from the $G$-metric properties that

(3) $3 / 2 G(x, y, y) \leq d_{G}(x, y) \leq 3 G(x, y, y)$ for all $x, y$ in $X$.

Definition 2.6 ([16]). A $G$-metric space $(X, G)$ is said to be $G$-complete if every $G$-Cauchy sequence in $(X, G)$ is $G$-convergent in $X$.

Proposition 2.5 ([16]). A G-metric space $(X, G)$ is $G$-complete if and only if $\left(X, d_{G}\right)$ is a complete metric space.

Definition 2.7 ([16]). Let ( $X, \preccurlyeq)$ be partially ordered set and $F: X \times X \rightarrow X$ be a mapping. The mapping $F: X \times X \rightarrow X$ is said to have mixed monotone property if $F$ is monotone nondecreasing in its fist argument and is monotone non-increasing in its second argument, that is, if for any $x_{1}, x_{2} \in X, x_{1} \leq x_{2}$ implies $F\left(x_{1}, y\right) \leq F\left(x_{2}, y\right)$ for $y \in X$ and for all $y_{1}, y_{2} \in X, y_{1} \leq y_{2}$ implies $F\left(x, y_{1}\right) \geq F\left(x, y_{2}\right)$.

Definition 2.8 ((Mixed g-monotone property [20])). Let $(X, \preccurlyeq)$ be partially ordered set and $F: X \times X \rightarrow X$ and $g: X \rightarrow X$ be two self mappings. $F$ has mixed $g$-monotone property if $F$ is monotone $g$-non-decreasing in its fist argument and is monotone $g$-non-increasing in its second argument, that is, if for any $x_{1}, x_{2} \in X, g x_{1} \leq g x_{2}$ implies $F\left(x_{1}, y\right) \leq F\left(x_{2}, y\right)$ for $y \in X$ and for all $y_{1}, y_{2} \in X, g y_{1} \leq g y_{2}$ implies $F\left(x, y_{1}\right) \geq F\left(x, y_{2}\right)$. 
Definition 2.9 ([16]). An element $(x, y) \in X \times X$, is called a coupled fixed point of mapping $F: X \times X \rightarrow X$ if $F(x, y)=x$ and $F(y, x)=y$.

Definition 2.10 ([16]). An element $(x, y) \in X \times X$, is called a coupled coincident point of mapping $F: X \times X \rightarrow X$ and $g: X \rightarrow X$ if $F(x, y)=g x$ and $F(y, x)=g y$.

Definition 2.11 ([27]). Let $(X, G)$ be a $G$-metric space. A mapping $F: X \times X \rightarrow X$ is said to be continuous if for any two $G$-convergent sequence $\left\{x_{n}\right\}$ and $\left\{y_{n}\right\}$ converging to $x$ and $y$ respectively, $\left\{F\left(x_{n}, y_{n}\right)\right\}$ is $G$-convergent to $F(x, y)$.

Using the concept of continuity, mixed monotone property and coupled fixed point, Choudhary and Maity [27] introduce the following theorem:

Theorem 2.1. Let $(X, \preccurlyeq)$ be partially ordered set and let $G$ be a $G$-metric on $X$ such that $(X, G)$ is a complete $G$-metric space. Let $F: X \times X \rightarrow X$ be a continuous mapping having mixed monotone property. Assume that there exist a $k \in[0,1)$ such that for $x, y, u, v, w, z \in X$, the following holds:

$$
G(F(x, y), F(u, v), F(w, z)) \leq \frac{k}{2}[G(x, u, w)+G(y, v, z)]
$$

for all $x \succcurlyeq u \succcurlyeq w$ and $y \preccurlyeq v \preccurlyeq z$ where either $u \neq w$ or $v \neq z$.

If there exist $x_{0}$ and $y_{0} \in X$, such that $x_{0} \preccurlyeq F\left(x_{0}, y_{0}\right)$ and $y_{0} \succcurlyeq F\left(y_{0}, x_{0}\right)$, then $F$ has coupled coincidence in $X$, that is, there exist $x, y \in X$ such that $x=F(x, y)$ and $y=F(y, x)$.

We define a notion of compatibility in the following:

Definition 2.12. The mappings $F$ and $g$ where $F: X \times X \rightarrow X$ and $g: X \rightarrow X$, are said to be compatible if

$$
\lim _{n \rightarrow \infty} G\left(g\left(F\left(x_{n}, y_{n}\right)\right), F\left(g x_{n}, g y_{n}\right), F\left(g x_{n}, g y_{n}\right)\right)=0
$$

and

$$
\lim _{n \rightarrow \infty} G\left(g\left(F\left(y_{n}, x_{n}\right)\right), F\left(g y_{n}, g x_{n}\right), F\left(g y_{n}, g x_{n}\right)\right)=0 .
$$

whenever $\left\{x_{n}\right\}$ and $\left\{y_{n}\right\}$ are sequences in $X$, such that $\lim _{n \rightarrow \infty} F\left(x_{n}, y_{n}\right)=\lim _{n \rightarrow \infty} g\left(x_{n}\right)=x$ and $\lim _{n \rightarrow \infty} F\left(y_{n}, x_{n}\right)=\lim _{n \rightarrow \infty} g\left(y_{n}\right)=y$, for all $x, y \in X$ are satisfied.

Definition 2.13 ([20]). We say that mappings $F: X \times X \rightarrow X$ and $g: X \rightarrow X$ are commutative if

$$
g(F(x, y))=F(g x, g y) \text { for all } x, y \in X
$$

We denote by $\Phi$ the set of function $\varphi:[0,+\infty) \rightarrow[0,+\infty)$ satisfying

(a) $\varphi^{-1}(\{0\})=\{0\}$, 
(b) $\varphi(t)<t$ for all $t>0$,

(c) $\lim _{r \rightarrow t^{+}} \varphi(r)<t$ for all $t>0$.

Lemma 2.1 ([20]). Let $\varphi \in \Phi$. For all $t>0$, we have $\lim _{n \rightarrow \infty} \varphi^{n}(t)=0$.

Now, we are ready to prove our result which is of three folds:

(i) We use compatibility which is more general that of continuity.

(ii) We proceed with $\varphi$-contraction which is more general.

(iii) We use mixed g-monotone property which generalizes mixed monotone property.

\section{Main results}

Theorem 3.1. Let $(X, \preccurlyeq)$ be partially ordered set and let $G$ be a $G$-metric on $X$ such that $(X, G)$ is a complete $G$-metric space. Let $\varphi:[0,1) \rightarrow[0,1)$ be such that $\varphi(r) \leq t$ and $\lim _{t \rightarrow r^{+}} \varphi(r)<t$ for all $t>0$. Let $F: X \times X \rightarrow X$ and $g: X \rightarrow X$ be two mappings such that $F$ has mixed $g$-monotone property and satisfy

$$
G(F(x, y), F(u, v), F(w, z)) \leq \varphi\left(\frac{G(g x, g u, g w)+G(g y, g v, g z)}{2}\right)
$$

for all $x, y, u, v, w, z \in X$, with $g w \preccurlyeq g u \preccurlyeq g x$ and $g y \preccurlyeq g v \preccurlyeq g z$, where either $u \neq w$ and $v \neq z$. Let $F(X \times X) \subseteq g(X), g$ be continuous and monotone increasing and $F$ and $g$ be compatible mappings. Also suppose

(a) F is continuous or

(b) X has the following property:

(i) if a non-decreasing sequence $\left\{x_{n}\right\} \rightarrow x$, then $x_{n} \preccurlyeq x$ for all $n \geq 0$.

(ii) if a non-increasing sequence $\left\{y_{n}\right\} \rightarrow y$, then $y \preccurlyeq y_{n}$ for all $n \geq 0$.

if there exist $x_{0}$ and $y_{0} \in X$, such that $g\left(x_{0}\right) \preccurlyeq F\left(x_{0}, y_{0}\right)$ and $g\left(y_{0}\right) \succcurlyeq F\left(y_{0}, x_{0}\right)$, then there exist $x, y \in X$ such that $g(x)=F(x, y)$ and $g(y)=F(y, x)$, that is, $F$ and $g$ have a coupled coincidence in $X$.

Proof. Let $x_{0}, y_{0}$ be such that $g x_{0} \preccurlyeq F\left(x_{0}, y_{0}\right)$ and $g y_{0} \succcurlyeq F\left(y_{0}, x_{0}\right)$. Since $F(X \times X) \subseteq g(X)$, we can choose $x_{1}, y_{1} \in X$ such that $g x_{1}=F\left(x_{0}, y_{0}\right)$ and $g y_{1}=F\left(y_{0}, x_{0}\right)$. Again we can choose $x_{2}, y_{2} \in X$ such that $g x_{2}=F\left(x_{1}, y_{1}\right)$ and $g y_{2}=F\left(y_{1}, x_{1}\right)$. Continuing like this we can construct two sequences $\left\{g x_{n}\right\}$ and $\left\{g y_{n}\right\}$ such that

$$
g x_{n}=F\left(x_{n-1}, y_{n-1}\right) \text { and } g y_{n}=F\left(y_{n-1}, x_{n-1}\right) \text { for all } n \geq 0 \text {. }
$$


We shall prove that for all $n \geq 0$,

$$
g x_{n} \preccurlyeq g x_{n+1} \text {, }
$$

and

$$
g y_{n} \succcurlyeq g y_{n+1} \text {. }
$$

Since $g x_{0} \preccurlyeq F\left(x_{0}, y_{0}\right)$ and $g y_{0} \succcurlyeq F\left(y_{0}, x_{0}\right)$ and $g x_{1}=F\left(x_{0}, y_{0}\right)$ and $g y_{1}=F\left(y_{0}, x_{0}\right)$, we have $g x_{0} \preccurlyeq g x_{1}$ and $g y_{0} \succcurlyeq g y_{1}$; that is, (3.3) and (3.4) hold for $n=0$.

We presume that (3.3) and (3.4) holds for some $n>0$. As $F$ has mixed g-monotone property and $g x_{n} \preccurlyeq g x_{n+1}, g y_{n} \succcurlyeq g y_{n+1}$, from (3.2), we have

$$
g x_{n+1}=F\left(x_{n}, y_{n}\right) \preccurlyeq F\left(x_{n+1}, y_{n}\right) \text { and } g y_{n+1}=F\left(y_{n}, x_{n}\right) \succcurlyeq F\left(y_{n+1}, x_{n}\right)
$$

Also for the same reason, we have

$$
F\left(x_{n+1}, y_{n}\right) \preccurlyeq F\left(x_{n+1}, y_{n+1}\right)=g x_{n+2} \quad \text { and } \quad F\left(y_{n+1}, x_{n}\right) \succcurlyeq F\left(y_{n+1}, x_{n+1}\right)=g y_{n+2} \text {. }
$$

From (3.3) and (3.4), we have that $g x_{n+1} \preccurlyeq g x_{n+2}$ and $g y_{n+1} \succcurlyeq g y_{n+2}$.

Then by mathematical induction it follows that (3.3) and (3.4) holds for $n \geq 0$. Therefore

$$
\begin{aligned}
& g x_{0} \preccurlyeq g x_{1} \preccurlyeq g x_{2} \preccurlyeq g x_{3} \preccurlyeq \ldots g x_{n} \preccurlyeq g x_{n+1} \preccurlyeq \ldots \\
& g y_{0} \succcurlyeq g y_{1} \succcurlyeq g y_{2} \succcurlyeq g y_{3} \succcurlyeq \ldots g y_{n} \succcurlyeq g y_{n+1} \succcurlyeq \ldots
\end{aligned}
$$

If for some $n$, we have $\left(g x_{n+1}, g y_{n+1}\right)=\left(g x_{n}, g y_{n}\right)$, then $g x_{n}=F\left(x_{n}, y_{n}\right)$ and $g y_{n}=F\left(y_{n}, x_{n}\right)$, that is, $F$ and $g$ have a coincidence point. So from now we assume $\left(g x_{n+1}, g y_{n+1}\right) \neq\left(g x_{n}, g y_{n}\right)$ for all $n \in N$, that is we assume that either $g x_{n+1}=F\left(x_{n}, y_{n}\right) \neq g x_{n}$ or $g y_{n+1}=F\left(y_{n}, x_{n}\right) \neq g y_{n}$.

Let, $\delta_{n}=G\left(g x_{n}, g x_{n+1}, g x_{n+1}\right)+G\left(g y_{n}, g y_{n+1}, g y_{n+1}\right)$.

Next, we prove that

$$
\delta_{n} \leq 2 \varphi\left(\frac{\delta_{n-1}}{2}\right) .
$$

Since for all $n \geq 0, g\left(x_{n-1}\right) \leq g\left(x_{n}\right)$ and $g\left(y_{n-1}\right) \geq g\left(y_{n}\right)$, we have from (3.1) and (3.2),

$$
\begin{aligned}
G\left(g x_{n}, g x_{n+1}, g x_{n+1}\right) & =G\left(F\left(x_{n-1}, y_{n-1}\right), F\left(x_{n}, y_{n}\right), F\left(x_{n}, y_{n}\right)\right) \\
& \leq \varphi\left(\frac{G\left(g x_{n-1}, g x_{n}, g x_{n}\right)+G\left(g y_{n-1}, g y_{n}, g y_{n}\right)}{2}\right) \\
& =\varphi\left(\frac{\delta_{n-1}}{2}\right)
\end{aligned}
$$

Similarly, we can obtain for $n \geq 0$,

$$
G\left(g y_{n}, g y_{n+1}, g y_{n+1}\right)=G\left(F\left(y_{n-1}, x_{n-1}\right), F\left(y_{n}, x_{n}\right), F\left(y_{n}, x_{n}\right)\right)
$$




$$
\begin{aligned}
& \leq \varphi\left(\frac{G\left(g y_{n-1}, g y_{n}, g y_{n}\right)+G\left(g x_{n-2}, g x_{n}, g x_{n}\right)}{2}\right) \\
& =\varphi\left(\frac{\delta_{n-1}}{2}\right)
\end{aligned}
$$

Combining (3.10) and (3.11), we get (3.9).

Since $\varphi(t)<t$ for all $t>0$, it follows from (3.9) that the sequence $\left\{\delta_{n}\right\}$ is a monotone decreasing sequence of non-negative real numbers. Hence, there exist $\delta>0$ such that $\lim _{n \rightarrow \infty} \delta_{n}=$ $\delta$. If possible, let $\delta>0$. Taking the limit as $n \rightarrow \infty$ in (3.9) and using $\lim _{t \rightarrow r^{+}} \varphi(r)<t$ for all $t>0$, we obtain

$$
\delta=\lim _{n \rightarrow \infty} \delta_{n} \leq 2 \lim _{n \rightarrow \infty} \varphi\left(\frac{\delta_{n-1}}{2}\right)=2 \lim _{\delta_{n-1} \rightarrow \delta^{+}} \varphi\left(\frac{\delta_{n-1}}{2}\right)<2 \cdot \frac{\delta}{2}
$$

which is a contradiction. Thus $\delta=0$. Hence we have

$$
\lim _{n \rightarrow \infty}\left[G\left(g x_{n}, g x_{n+1}, g x_{n+1}\right)+G\left(g y_{n}, g y_{n+1}, g y_{n+1}\right)\right]=\lim _{n \rightarrow \infty} \delta_{n}=0 .
$$

Next we show that $\left\{g x_{n}\right\}$ and $\left\{g y_{n}\right\}$ are $G$-Cauchy sequences. Let at least one of $\left\{g x_{n}\right\}$ and $\left\{g y_{n}\right\}$ be not a $G$-Cauchy sequence. Then there exist $\varepsilon>0$ and the sequence of natural numbers $\{m(k)\}$ and $\{l(k)\}$ such that for every natural number $k, m(k)>l(k) \geq k$ and

$$
G_{k}=G\left(g x_{l(k)}, g x_{m(k)}, g x_{m(k)}\right)+G\left(g y_{l(k)}, g y_{m(k)}, g y_{m(k)}\right) \geq \varepsilon .
$$

Now corresponding to $l(k)$, we can choose $m(k)$ to be smallest positive integer for which (3.12) holds. Then,

$$
G\left(g x_{l(k)}, g x_{m(k)-1}, g x_{m(k)-1}\right)+G\left(g y_{l(k)}, g y_{m(k)-1}, g y_{m(k)-1}\right)<\varepsilon .
$$

Further from (3.12), (3.13) and rectangular inequality of $G$-metric space, for all $k \geq 0$, we have

$$
\begin{aligned}
\varepsilon \leq G_{k} \leq & G\left(g x_{l(k)}, g x_{m(k)-1}, g x_{m(k)-1}\right)+G\left(g x_{m(k)-1}, g x_{m(k)}, g x_{m(k)}\right) \\
& +G\left(g y_{l(k)}, g y_{m(k)-1}, g y_{m(k)-1}\right)+G\left(g y_{m(k)-1}, g y_{m(k)}, g y_{m(k)}\right) \\
= & G\left(g x_{l(k)}, g x_{m(k)-1}, g x_{m(k)-1}\right)+G\left(g y_{l(k)}, g y_{m(k)-1}, g y_{m(k)-1}\right)+\delta_{m(k)-1} \\
< & \varepsilon+\delta_{m(k)-1}
\end{aligned}
$$

Taking the limit as $k \rightarrow \infty$, we have by (3.12),

$$
\lim _{k \rightarrow \infty} G_{k}=\varepsilon
$$

Again, for all $k \geq 0$, we have

$$
\begin{aligned}
G_{k} & =G\left(g x_{l(k)}, g x_{m(k)}, g x_{m(k)}\right)+G\left(g y_{l(k)}, g y_{m(k)}, g y_{m(k)}\right) \\
& \leq G\left(g x_{l(k)}, g x_{l(k)+1}, g x_{l(k)+1}\right)+G\left(g x_{l(k)+1}, g x_{m(k)+1}, g x_{m(k)+1}\right)
\end{aligned}
$$




$$
\begin{aligned}
& +G\left(g x_{m(k)+1}, g x_{m(k)}, g x_{m(k)}\right)+G\left(g y_{l(k)}, g y_{l(k)+1}, g y_{l(k)+1}\right) \\
& +G\left(g y_{l(k)+1}, g y_{m(k)+1}, g y_{m(k)+1}\right)+G\left(g y_{m(k)+1}, g y_{m(k)}, g y_{m(k)}\right) \\
= & G\left(g x_{l(k)}, g x_{l(k)+1}, g x_{l(k)+1}\right)+G\left(g y_{l(k)}, g y_{l(k)+1}, g y_{l(k)+1}\right) \\
& +G\left(g x_{l(k)+1}, g x_{m(k)+1}, g x_{m(k)+1}\right)+G\left(g y_{l(k)+1}, g y_{m(k)+1}, g y_{m(k)+1}\right) \\
& +G\left(g x_{m(k)+1}, g x_{m(k)}, g x_{m(k)}\right)+G\left(g y_{m(k)+1}, g y_{m(k)}, g y_{m(k)}\right)
\end{aligned}
$$

Hence, for all $k \geq 0$

$$
G_{k} \leq \delta_{l(k)}+\delta_{m(k)}+G\left(g x_{l(k)+1}, g x_{m(k)+1}, g x_{m(k)+1}\right)+G\left(g y_{l(k)+1}, g y_{m(k)+1}, g y_{m(k)+1}\right) \text {. }
$$

From (3.1), (3.2) and (3.12), for all $k \geq 0$, we obtain

$$
\begin{aligned}
G( & \left.g x_{l(k)+1}, g x_{m(k)+1}, g x_{m(k)+1}\right) \\
& =G\left(F\left(g x_{l(k)}, g y_{l(k)}\right), F\left(g x_{m(k)}, g y_{m(k)}\right), F\left(g x_{m(k)}, g y_{m(k)}\right)\right) \\
& \leq \varphi\left(\frac{G\left(g x_{l(k)}, g x_{m(k)}, g x_{m(k)}\right)+G\left(g y_{l(k)}, g y_{m(k)}, g y_{m(k)}\right)}{2}\right) \\
& =\varphi\left(\frac{G k}{2}\right) .
\end{aligned}
$$

Also by (3.1), (3.2) and (3.12), for all $k \geq 0$, we have

$$
\begin{aligned}
G & \left(g y_{l(k)+1}, g y_{m(k)+1}, g y_{m(k)+1}\right) \\
& =G\left(F\left(g y_{l(k)}, g x_{l(k)}\right), F\left(g y_{m(k)}, g x_{m(k)}\right), F\left(g y_{m(k)}, g x_{m(k)}\right)\right) \\
& \leq \varphi\left(\frac{G\left(g y_{l(k)}, g y_{m(k)}, g y_{m(k)}\right)+G\left(g x_{l(k)}, g x_{m(k)}, g x_{m(k)}\right)}{2}\right) \\
& =\varphi\left(\frac{G k}{2}\right) .
\end{aligned}
$$

Putting (3.16) and (3.20) in (3.15), for all $k \geq 0$, we obtain,

$$
G_{k} \leq \delta_{l(k)}+\delta_{m(k)}+2 \varphi\left(\frac{G_{k}}{2}\right)
$$

Letting $n \rightarrow \infty$ in the above inequality and using (3.12)-(3.14), we obtain

$$
\varepsilon \leq \lim _{k \rightarrow \infty} \varphi\left(\frac{G_{k}}{2}\right)=2 \lim _{G_{k^{\rightarrow} \varepsilon^{+}}} \varphi\left(\frac{G_{k}}{2}\right)<2 \cdot \frac{\varepsilon}{2}=\varepsilon,
$$

which is a contradiction. Therefore, $\left\{g x_{n}\right\}$ and $\left\{g y_{n}\right\}$ are $G$-Cauchy sequences in $X$ and hence they are convergent in complete $G$-metric space $(X, G)$. Let

$$
\lim _{n \rightarrow \infty} F\left(x_{n}, y_{n}\right)=g x_{n}=x \text { and } \lim _{n \rightarrow \infty} F\left(y_{n}, x_{n}\right)=g y_{n}=y .
$$

Since, $F$ and $g$ are compatible mappings; we have by (3.21),

$$
\lim _{n \rightarrow \infty} G\left(g\left(F\left(x_{n}, y_{n}\right)\right), F\left(g x_{n}, g y_{n}\right), F\left(g x_{n}, g y_{n}\right)\right)=0
$$


and

$$
\lim _{n \rightarrow \infty} G\left(g\left(F\left(y_{n}, x_{n}\right)\right), F\left(g y_{n}, g x_{n}\right), F\left(g y_{n}, g x_{n}\right)\right)=0
$$

Next we prove that $g x=F(x, y)$ and $g y=F(y, x)$.

Let (a) hold.

For all $n \geq 0$, we have

$$
\begin{aligned}
G\left(g x, F\left(g x_{n}, g y_{n}\right), F\left(g x_{n}, g y_{n}\right)\right) \leq & G\left(g x, g\left(F\left(x_{n}, y_{n}\right)\right), g\left(F\left(x_{n}, y_{n}\right)\right)\right) \\
& +G\left(g\left(F\left(x_{n}, y_{n}\right)\right), F\left(g x_{n}, g y_{n}\right), F\left(g x_{n}, g y_{n}\right)\right) .
\end{aligned}
$$

Taking the limit as $n \rightarrow \infty$ using (3.2), (3.22), (3.23) and the fact that $F$ and $g$ are continuous, we have $G(x, F(x, y), F(x, y)=0$.

Similarly, we have $G(x, F(x, y), F(x, y)=0$.

Combining the above two results we get $g x=F(x, y)$ and $g y=F(y, x)$.

Next we suppose that (b) holds.

By (3.8) and (3.21), we have $\left\{g x_{n}\right\}$ is non-decreasing sequence, $g\left(x_{n}\right) \rightarrow x$ and $\left\{g y_{n}\right\}$ is non-increasing sequence, $g\left(y_{n}\right) \rightarrow y$ as $n \rightarrow \infty$. Then by (i) and (ii) of condition (b), we have for $n \geq 0$,

$$
g\left(x_{n}\right) \preccurlyeq x \text { and } g\left(y_{n}\right) \succcurlyeq y \text {. }
$$

Since, $F$ and $g$ are compatible mappings and $g$ is continuous, by (3.22) and (3.23), we have

and

$$
\lim _{n \rightarrow \infty} g\left(g x_{n}\right)=g x=\lim _{n \rightarrow \infty} g\left(F\left(x_{n}, y_{n}\right)\right)=\lim _{n \rightarrow \infty} F\left(g x_{n}, g y_{n}\right)
$$

$$
\lim _{n \rightarrow \infty} g\left(g y_{n}\right)=g y=\lim _{n \rightarrow \infty} g\left(F\left(y_{n}, x_{n}\right)\right)=\lim _{n \rightarrow \infty} F\left(g y_{n}, g x_{n}\right) .
$$

Now we have by rectangular inequality of $G$-metric space

$$
G(g x, F(x, y), F(x, y)) \leq G\left(g x, g\left(g x_{n+1}\right), g\left(g x_{n+1}\right)\right)+G\left(g\left(g x_{n+1}\right), F(x, y), F(x, y)\right) \text {. }
$$

Taking the limit as $n \rightarrow \infty$ in the above inequality, using (3.2) and (3.20) we have,

$$
\begin{aligned}
G(g x, F(x, y), F(x, y)) & \leq \lim _{n \rightarrow \infty} G\left(g x, g\left(g x_{n+1}\right), g\left(g x_{n+1}\right)\right)+\lim _{n \rightarrow \infty} G\left(g\left(g x_{n+1}\right), F(x, y), F(x, y)\right) \\
& \leq \lim _{n \rightarrow \infty} G\left(F\left(g x_{n}, g y_{n}\right), F(x, y), F(x, y)\right) .
\end{aligned}
$$

Since the mapping $\mathrm{g}$ is monotone increasing, by (3.1) and (3.16), we have

$$
G(g x, F(x, y), F(x, y)) \leq \lim _{n \rightarrow \infty} \varphi\left(\frac{G\left(g\left(g x_{n}\right), g x, g x\right)+G\left(g\left(g y_{n}\right), g y, g y\right)}{2}\right)
$$

Using, (3.21) and the property of $\varphi$-function we obtain, $G(g x, F(x, y), F(x, y)) \leq 0$. 
That is

$$
g(x)=F(x, y)
$$

and similarly, by virtue of (3.2), (3.21) and (3.26), we obtain

$$
g(y)=F(y, x)
$$

Thus we have proved that $F$ and $g$ have coupled coincidence point in $X$.

This completes the proof of the Theorem 3.1.

Remark 1. If we assume $g(x)=x$ for all $x \in X$ and $\varphi(t)=k t$ for $0 \leq k<1$, then we obtain the result of Choudhary and Maity which is noted here in Theorem 2.1.

Example 1. Let $X=[0,1]$, then $(X, \preccurlyeq)$ is a partially ordered set with natural ordering of real numbers. Let

$$
G(x, y, z)=(|x-y|+|y-z|+|z-x|), \quad \text { for } \quad x, y, z \in X .
$$

Then $(X, d)$ is a complete $G$-metric space.

Let $g: X \rightarrow X$ be defined as

$$
g(x)=x, \text { for all } x \text { in } X
$$

Let

$$
F(x, y)= \begin{cases}\left(\frac{x-y}{2}\right)^{2}, & \text { if } x, y \in[0,1], x \geq y \\ 0, & \text { if } x<y\end{cases}
$$

Clearly, $F(X \times X) \subseteq g(X)$, also $F$ obeys mixed $g$-monotone property.

If we define $f:[0,+\infty) \rightarrow[0,+\infty)$ as $f(t)=\frac{2}{3} t$, for $t \in[0,+\infty)$.

It is obvious that all the condition of Theorem 3.1 is satisfied. Hence $(0,0)$ is the coupled coincidence point of $F$ and $g$.

Remark 2. It is obvious that the mapping $F$ and $G$ are not commuting, then this example will not be applicable which proves the generality of our result.

\section{References}

[1] Z. Mustafa and B. Sims, Some remark concerning D-metric spaces, Proc. Int. Conf. on Fixed Point Theor. Appl., Valencia, Spain, July 2003, 189-198.

[2] Z. Mustafa and B. Sims, A new approach to generalized metric spaces, J. Nonlinear Convex Anal., 7(2) (2006), 289-297.

[3] Z. Mustafa, H. Obiedat and F. Awawdeh, Some of fixed point theorem for mapping on complete G-metric spaces, Fixed Point Theory Appl., 12(2008), Article ID 189870. 
[4] Z. Mustafa, W. Shatanawi and M. Bataineh, Fixed point theorems on complete G-metric spaces, J. Math. Stat. 4(4) (2008), 196-201.

[5] Z. Mustafa, W. Shatanawi and M. Bataineh, Existence offixed point result in G-metric space, Int. J. Math. Math. Sci., 10(2009), Article ID 283028.

[6] Z. Mustafa and B. Sims, Fixed point theorem for contractive mapping in G-metric space, Fixed Point Theory Appl. 10(2009), Article ID 917175.

[7] M. Abbas and B. E. Rhoades, Common fixed point results for noncommuting mappings without continuity in generalized metric spaces, Appl. Math. Comput., 215 (2009), 262-269.

[8] R. Saadati, S. M. Vaezpour, P. Vetro and B. E. Rhoades, Fixed point theorem in generalized partially ordered G-metric spaces, Math. Comput. Modelling, 52(2010), 797-801.

[9] R. K. Vats. S. Kumar and V. Sihag, Some common fixed point theorem for compatible mapping of type (A) in complete G-metric spaces, Adv. Fuzzy Math., 627-38.

[10] R. Chugh, T. Kadian, A. Rani and B. E. Rhoades, Property P in G-metric space, Fixed Point Theory Appl., 12 (2010), Article ID 401684.

[11] M. Abbas, T. Nazir and S. Radenovic, Some periodic point result in generalized metric spaces, Appl. Math. Comput., 217(2010) 4094-4099.

[12] T. Kamran, N. Cakic, Hybrid tangential property and coincidence point theorems, Fixed Point Theory, $\mathbf{9}$ (2008), 487-497.

[13] Lj. Ciric, N. Cakic, On common fixed point theorems for non-self hybrid mappings in convex metric spaces, Appl. Math. Comput., 208(2009), 90-97.

[14] A. C. M. Ran and M. C. B. Reurings, A fixed point theorem in partially ordered sets and some application to metric equations, Proc. Amer. Math. Soc., 132 (2004), 1435-1443.

[15] J. J. Nieto and R. Rodrigues-Lopez, Contractive mapping theorems in partially ordered sets and application to ordinary differential equations, Order 22 (2005), 223-239.

[16] T. Gnana. Bhaskar and V. Lakshmikanthan, Fixed point theorem in partially ordered metric spaces and applications, Nonlinear Anal. TMA, 65 (2006), 1379-1393.

[17] J. J. Nieto and R. R. Lopez, Existence and uniqueness of fixed point in partially ordered sets and application to ordinary differential equation, Acta Math. Sin., 23 (2007), 2205-2212.

[18] L. Ciric, N. Cakic, M. Rajovic and J. S. Ume, Monotone generalized nonlinear contraction in partially ordered metric spaces, Fixed Point Theory Appl., 11 (2008), Article ID 131294.

[19] J. Harjani, K. Sadarangani, Fixed point theorems for weakly contractive mappings in partially ordered sets, Nonlinear Anal., 71 (2009), 3403-3410.

[20] L. Ciric. V. Lakshmikanthan, Coupled random fixed point theorems for nonlinear contractions in partially ordered metric spaces, Stoch. Anal. Appl., 27 (2009), 1246-1259.

[21] V. Lakshmikanthan and L. Ciric, Coupled fixed point theorems for nonlinear contractions in partially ordered metric spaces, Nonlinear Anal. TMA, 70 (2009), 4341-4349.

[22] J. Harjani and K. Sadarangani, Generalized contraction in partially ordered metric space and application to ordinary differential equation, Nonlinear Anal., 72 (2010), 1188-1197.

[23] B. Samet, Coupled fixed point theorems for a generalized Meir-Keeler contraction in partially ordered metric spaces, Nonlinear Anal. 72(2010), 4508-4517.

[24] E. Karapinar, Coupled fixed point theorem for nonlinear contractions in cone metric spaces, Comput. Math. Appl., 59 (2010), 3656-3668.

[25] M. Abbas, M. Ali Khan and S. Radenovic, Common coupled fixed point theorem in cone metric spaces for w-compatible mappings, Appl. Math. Comput., 217 (2010), 195-202.

[26] B. S. Choudhary and A. Kundu, A coupled coincidence point result in partially ordered metric spaces for compatible mappings, Nonlinear Anal., 73 (2010), 2524-2531.

[27] B. S. Choudhary and P. Maity, Coupled fixed point results in generalized metric spaces, Math. Comput. Modelling, 54 (2011), 73-79.

Department of Mathematics, National Institute of Technology, Hamirpur (H.P.)-177005, India.

E-mail: vsihag3@gmail.com

E-mail: ramesh_vats@rediffmail.com 